\title{
Large-area uniform graphene-like thin films grown by chemical vapor deposition directly on silicon nitride
}

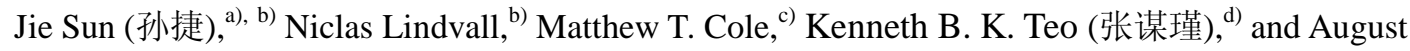 \\ Yurgens s) $^{\text {b) }}$ \\ ${ }^{b)}$ Quantum Device Physics Laboratory, Department of Microtechnology and Nanoscience, Chalmers University of
} Technology, S-41296 Gothenburg, Sweden

${ }^{c)}$ Electrical Engineering Division, Engineering Department, University of Cambridge, 9 JJ Thomson Avenue, CB3 OFA, Cambridge, United Kingdom

${ }^{d)}$ AIXTRON Nanoinstruments Ltd., Swavesey, Cambridge, CB24 4FQ, United Kingdom

\begin{abstract}
Large-area uniform carbon films with graphene-like properties are synthesized by chemical vapor deposition directly on $\mathrm{Si}_{3} \mathrm{~N}_{4} / \mathrm{Si}$ at $1000{ }^{\circ} \mathrm{C}$ without metal catalysts. The as-deposited films are atomically thin and wrinkle- and pinhole-free. The film thickness can be controlled by modifying the growth conditions. Raman spectroscopy confirms the $s p^{2}$ graphitic structures. The films show ohmic behavior with a sheet resistance of $\sim 2.3-10.5 \mathrm{k} \Omega / \square$ at room temperature. An electric field effect of $\sim 2-10 \%\left(V_{G}=-20 \mathrm{~V}\right)$ is observed. The growth is explained by the self-assembly of carbon clusters from hydrocarbon pyrolysis. The scalable and transfer-free technique favors the application of graphene as transparent electrodes.
\end{abstract}

\footnotetext{
a) Author to whom correspondence should be addressed. Electronic mail: albertjefferson@ sohu.com, jiesu@chalmers.se.
} 
Graphene is a monolayer of $s p^{2}$ hybridized carbon atoms forming a two-dimensional hexagonal crystal lattice. Graphene has received much attention since $2004 .^{1}$ Due to its extraordinary properties, graphene is considered to be one of the candidate materials for post-silicon nanoelectronics. ${ }^{2}$ For instance, by virtue of its high optical transparency and high carrier mobility, graphene can be used in transparent electrodes and ultrafast transistors. ${ }^{3,4}$ However, while mechanical exfoliation is still widely used to fabricate graphene, the flakes are far too small and irregular for practical applications. Today, there are two common alternative techniques for large-area graphene synthesis. One is the high-temperature annealing of $\mathrm{SiC}$ which results in the desorption of Si from the surface leaving excess carbon behind. ${ }^{5}$ This method, however, suffers from the lack of availability of large, inexpensive SiC substrates. Another more promising technique in terms of scalability is chemical vapor deposition (CVD) on metals from hydrocarbon precursors. It is fully compatible with the existing semiconductor processes, and has shown significant potential as a cost effective route toward producing high-quality graphene. Commonly, graphene is grown on $\mathrm{Ni}^{6,7}$ or $\mathrm{Cu}^{8-11}$ catalysts. For most electronic applications, however, the as-synthesized graphene must be transferred to various dielectric substrates, inevitably resulting in wrinkles, holes and metal etching residues. Thus, there is a substantial need to develop a scalable method for reliable production of large-area graphene directly on insulating substrates.

Previously, we have demonstrated that graphene-like thin films can be synthesized by CVD directly on silicon dioxide $\left(300 \mathrm{~nm} \text { thermal } \mathrm{SiO}_{2} \text { on } \mathrm{Si}\right)^{12}$ or hafnium dioxide $(320 \mathrm{~nm}$ atomic layer deposited $\mathrm{HfO}_{2}$ on $\left.\mathrm{Si}\right),{ }^{13-15}$ which is promising in applications such as transparent electrodes. Graphene-like thin films can also be realized on nitrides such as $\mathrm{GaN}^{16}$ and $\mathrm{BN} .{ }^{17}$ However, the electrical properties of these films on nitrides are unknown. This letter reports the synthesis and 
electronic characterization of large-area uniform graphene-like thin films by CVD directly on a silicon nitride substrate. Although $\mathrm{Si}_{3} \mathrm{~N}_{4}$ has a larger number of bulk traps compared with $\mathrm{SiO}_{2}$, it has higher resistivity $\left(10^{16} \Omega \cdot \mathrm{cm}\right)$ and dielectric strength $(10 \mathrm{MV} / \mathrm{cm})$ than most insulators commonly available in microelectronics. ${ }^{18}$ The thickness of the as-deposited films on $\mathrm{Si}_{3} \mathrm{~N}_{4}$, which can be reduced to be atomically thin, is controlled by tuning the deposition time and/or the carbon precursor partial pressure. The films are termed "graphene-like" because of the optical and electrical similarity to metal-catalyzed graphene. However, the quality of the thin films requires continued optimization in terms of crystallinity and carrier mobility. The $s p^{2}-\mathrm{C}$ structure was confirmed by Raman spectroscopy. At room temperature, the thin films showed ohmic behavior and electric field effect. This transfer-free process results in highly reproducible fabrication and favors the industrialization of graphene-based technology.

$\mathrm{Si}_{3} \mathrm{~N}_{4}$ thin films $(100 \mathrm{~nm})$ grown at $770{ }^{\circ} \mathrm{C}$ from $\mathrm{SiCl}_{2} \mathrm{H}_{2}$ and $\mathrm{NH}_{3}$ precursors by low-pressure CVD (Centrotherm) on Si were used as the substrates. The graphene-like thin films were produced in a home-built hot-wall CVD system under atmospheric pressure. The $\mathrm{Si}_{3} \mathrm{~N}_{4} / \mathrm{Si}$ substrates were heated to $1000{ }^{\circ} \mathrm{C}$ in a flow of $50 \mathrm{sccm}$ hydrogen and $1000 \mathrm{sccm}$ argon. The samples were kept at $1000{ }^{\circ} \mathrm{C}$ for $3 \mathrm{~min}$. Then, $300 \mathrm{sccm}$ methane was introduced into the chamber to initiate the deposition. The growth time was $30 \mathrm{~min}$ for sample A and $45 \mathrm{~min}$ for sample B. Sample C was grown at $\mathrm{CH}_{4}: \mathrm{H}_{2}=1000: 50 \mathrm{sccm}$ (no Ar) at $1000{ }^{\circ} \mathrm{C}$ for 30 min. After growth, the $\mathrm{CH}_{4}$ flow was terminated, and the system was held at high temperature for a further 3 min before ambient cooling to room temperature in the same $\mathrm{H}_{2}+\mathrm{Ar}$ atmosphere. The temperature profile for the deposition of sample A is depicted in Fig. 1. To test the reproducibility, the growth of graphene-like thin films on $\mathrm{Si}_{3} \mathrm{~N}_{4} / \mathrm{Si}$ was repeated in a cold-wall low-pressure CVD system (Black 
Magic, AIXTRON). The deposition temperature was $1000{ }^{\circ} \mathrm{C}$ with $\mathrm{C}_{2} \mathrm{H}_{2}$ as the precursor. A 30 min deposition at $20 \mathrm{sccm} \mathrm{C}_{2} \mathrm{H}_{2}, 20 \mathrm{sccm} \mathrm{H}_{2}$ and $1000 \mathrm{sccm}$ Ar produced graphene-like thin films similar to sample A in terms of optical and electrical properties.

The Raman spectra of the thin films grown directly on $\mathrm{Si}_{3} \mathrm{~N}_{4} / \mathrm{Si}$ are summarized in Fig. 2. The $\mathrm{G}$ band centered at $\sim 1604 \mathrm{~cm}^{-1}$ and the $2 \mathrm{D}$ band at $\sim 2704 \mathrm{~cm}^{-1}$ are clearly resolved for all samples. The G- and 2D bands are Raman signatures of $s p^{2}$ graphitic materials. ${ }^{19}$ The well-defined peaks differentiate the thin films from amorphous carbon $(a-C) .{ }^{19}$ The D band at $\sim 1349 \mathrm{~cm}^{-1}$ and the $\mathrm{G}+\mathrm{D}$ band (higher order Raman signals) at $\sim 2953 \mathrm{~cm}^{-1}$ are also noted. The large D band indicates the high defect densities within the as-synthesized thin films. The graphene-like films on samples $\mathrm{A}$ and $\mathrm{B}$ are much thinner than sample $\mathrm{C}$ because of the lower $\mathrm{CH}_{4}$ concentration. As a result, spectral features associated with the substrate were detected at approximately $1000 \mathrm{~cm}^{-1}$.

An overview of the samples is shown in Fig. 3(a). The bare $\mathrm{Si}_{3} \mathrm{~N}_{4} / \mathrm{Si}$, samples $\mathrm{A}_{1}$ and $\mathrm{B}$ are in the upper row; sample $\mathrm{C}$ and sample $\mathrm{A}_{2}$ (after device processing) are in the lower row. After the growth, there was no apparent change in color except for sample C. Fig. 3(b) shows an optical image of a device made on sample A by traditional photolithography using a Shipley S1813 resist. A rather weak contrast between the graphene-like thin film and $\mathrm{Si}_{3} \mathrm{~N}_{4} / \mathrm{Si}$ can be seen at this scale. Atomic force microscopy line-scans across the steps in the fabricated devices indicate that the thickness of the thin films was $\sim 2,4$ and $70 \mathrm{~nm}$ for samples A, B and C, respectively. It is known that exfoliated monolayer graphene typically has a height of $0.6-0.8 \mathrm{~nm}^{20}$ which often increases to $\sim 2 \mathrm{~nm}$ after lithographic processing. ${ }^{21,22}$ Samples A and B have depths that are largely consistent with these values, which may correspond to monolayer and few-layer graphene-like thin films, respectively. Sample C is a shiny-gray graphite-like film. Clearly, the number of graphene layers 
in the thin films increases as the deposition time and/or C precursor partial pressure increases, permitting accurate control over the film thickness. Neither wrinkles nor pinholes are observed in the deposited thin films in Fig. 3, implying a high degree of macroscopic uniformity.

Room temperature electrical measurements were performed on samples A, B and C. In Fig. 3(b), electrodes $(5 \mathrm{~nm} \mathrm{Cr} / 45 \mathrm{~nm} \mathrm{Au})$ in the Hall-bar structures were used for current biasing (left and right) and voltage probing (upper and lower). The device active area was $4 \times 4 \mu \mathrm{m}^{2}$. Figs. 4 (a) and (b) show the measured properties of samples A and B, respectively. Linear $I-V$ curves (at zero gate voltage) were obtained for all three samples, indicating an ohmic behavior of the thin films and their contacts with metals. Four-terminal resistance measurement gave the sheet resistance $R_{s}$ of $\sim 10.5,2.3$ and $0.15 \mathrm{k} \Omega / \square$ for samples A, B and C, respectively. The $R_{s}$ values of samples A and B are comparable to that of $\mathrm{Cu}$-catalyzed graphene. ${ }^{8-11}$ Fig. 4 also shows $R_{s}$ versus the back-gate voltage $V_{G}(-20 \mathrm{~V}$ to $38 \mathrm{~V})$ applied to the doped $\mathrm{Si}$ substrate. The dielectric properties of the $\mathrm{Si}_{3} \mathrm{~N}_{4}$ films were changed by the lengthy high temperature CVD, and therefore higher $V_{G}$ may lead to the breakdown of $\mathrm{Si}_{3} \mathrm{~N}_{4}$. Electric field effects of $10.38 \%$ and $2.48 \%$ were observed at $V_{G}=-20 \mathrm{~V}$ in samples A and B, respectively, whereas no field effect was seen in sample C. Here, the field effect is quantified by $\Delta \Sigma_{s} / \Sigma_{s}(0)=\left[\Sigma_{s}\left(V_{G}\right)-\Sigma_{s}(0)\right] / \Sigma_{s}(0)$, where $\Sigma_{s}=1 / R_{s}{ }^{1,23}$ The Dirac point was not seen over this $V_{G}$ range, possibly related to the charge doping effect associated with photoresist residues. ${ }^{24}$ Nevertheless, a down-bending trend in the curves was observed, implying the possible ambipolar behavior of the materials. By virtue of a thinner dielectric with higher $k$ value, the field effect observed here was more pronounced compared to the graphene-like thin films deposited directly on $\mathrm{SiO}_{2}{ }^{12}$

To date, graphitization on insulators has rarely been studied and the mechanism associated with 
it is not well understood. Some authors suggest that the substrates play a catalytic role. ${ }^{25}$ However, in this letter, a different explanation is proposed, because there is no direct evidence of the catalytic chemical reaction. In this case, the CVD of graphene-like thin films is much more likely a self-assembly process of $\mathrm{C}$ clusters, resulting from the pyrolysis of the hydrocarbon precursor. At $1000{ }^{\circ} \mathrm{C}$, most $\mathrm{CH}_{4}$ molecules thermally decompose, liberating the $\mathrm{C}$ atoms, which arrange themselves, through thermal activation, into hexagonal structures forming $s p^{2}$ hybridized graphene flakes $(\sim 10-100 \mathrm{~nm})$. Usually, these flakes chaotically aggregate into large porous lumps, as is widely used in industry for the large-scale production of carbon black. ${ }^{26}$ Nevertheless, under our conditions, hot flat substrates allow the graphene flakes to self-organize into continuous textured thin films. This process, however, is a slow procedure, requiring longer deposition time and higher $\mathrm{CH}_{4}$ concentration compared with the catalytic $\mathrm{CVD}$ of graphene, on $\mathrm{Cu}$ for example. The crystallinity of the as-synthesized graphene-like thin films is relatively poor compared to $\mathrm{Cu}$-catalyzed graphene, but is still significantly superior to atomically thin $a$-C. ${ }^{27}$ The graphene-like thin films produced here are electrically conducting and optically transparent, and hence are promising in applications involving transparent electrodes. They can be grown on virtually any substrate that can withstand the high temperature processing at $\sim 1000{ }^{\circ} \mathrm{C}$. Indeed, it was found that large-area uniform graphene-like thin films with controlled thickness can be deposited on sapphire, quartz, mica, etc.

In conclusion, uniform large-area carbon thin films with graphene-like properties were synthesized directly on silicon nitride by $\mathrm{CVD}$ using $\mathrm{CH}_{4}$ or $\mathrm{C}_{2} \mathrm{H}_{2}$ as precursors. The thin films show a high degree of topographic uniformity, with no observable wrinkles or pinholes. The $s p^{2}-\mathrm{C}$ network was confirmed by Raman spectroscopy. At room temperature, the thin films were ohmic 
and showed a modest field effect. This work demonstrates the feasibility of directly forming graphene-like thin films on $\mathrm{Si}_{3} \mathrm{~N}_{4}$ and other dielectric substrates by CVD and favors the industrialization of graphene-based materials in applications such as transparent electrodes.

The authors thank Prof. J. Liu and T. Wang at Chalmers and Dr. J. Svensson at Lund for their help with CVD systems. Financial support from the Swedish Research Council and the Swedish Foundation for Strategic Research is greatly appreciated. M. T. Cole wishes to thank the Schiff studentship and St. John's College Cambridge for generous financial support. The CVD growth and other clean-room processing were performed on the equipments funded by the Knut and Alice Wallenberg Foundation. 
1 K. S. Novoselov, A. K. Geim, S. V. Morozov, D. Jiang, Y. Zhang, S. V. Dubonos, I. V. Grigorieva, and A. A. Firsov, Science 306, 666 (2004).

2 F. Schwierz, Nature Nanotechnol. 5, 487 (2010).

3 S. Bae, H. Kim, Y. Lee, X. Xu, J.-S. Park, Y. Zheng, J. Balakrishnan, T. Lei, H. R. Kim, Y. I. Song, Y.-J. Kim, K. S. Kim, B. Ozyilmaz, J.-H. Ahn, B. H. Hong, and S. Iijima, Nature Nanotechnol. 5, 574 (2010).

4 Y.-M. Lin, C. Dimitrakopoulos, K. A. Jenkins, D. B. Farmer, H.-Y. Chiu, A. Grill, and Ph. Avouris, Science 327, 662 (2010).

5 J. Hass, W. A. de Heer, and E. H. Conrad, J. Phys.: Condens. Matter 20, 323202 (2008).

6 A. Reina, X. Jia, J. Ho, D. Nezich, H. Son, V. Bulovic, M. S. Dresselhaus, and J. Kong, Nano Lett. 9, 30 (2009).

7 K. S. Kim, Y. Zhao, H. Jang, S. Y. Lee, J. M. Kim, K. S. Kim, J.-H. Ahn, P. Kim, J.-Y. Choi, and B. H. Hong, Nature 457, 706 (2009).

8 C.-A. Di, D. Wei, G. Yu, Y. Liu, Y. Guo, and D. Zhu, Adv. Mater. 20, 3289 (2008).

9 X. Li, W. Cai, J. An, S. Kim, J. Nah, D. Yang, R. Piner, A. Velamakanni, I. Jung, E. Tutuc, S. K. Banerjee, L. Colombo, and R. S. Ruoff, Science 324, 1312 (2009).

10 M. P. Levendorf, C. S. Ruiz-Vargas, S. Garg, and J. Park, Nano Lett. 9, 4479 (2009).

11 H. Cao, Q. Yu, L. A. Jauregui, J. Tian, W. Wu, Z. Liu, R. Jalilian, D. K. Benjamin, Z. Jiang, J. Bao, S. S. Pei, and Y. P. Chen, Appl. Phys. Lett. 96, 122106 (2010).

12 J. Sun et al., to be published.

13 J. Sun, M. Larsson, I. Maximov, and H. Q. Xu, Appl. Phys. Lett. 96, 162107 (2010).

14 J. Sun, E. Lind, I. Maximov, and H. Q. Xu, IEEE Electron Device Lett. 32, 131 (2011). 
15 See supplementary material at http://dx.doi.org/ for details about graphene-like thin films on $\mathrm{HfO}_{2}$.

16 W. Han and A. Zettl, Adv. Mater. 14, 1560 (2002).

17 X. Ding, G. Ding, X. Xie, F. Huang and M. Jiang, Carbon 49, 2522 (2011).

18 Y. Nishi and R. Doering, Handbook of Semiconductor Manufacturing Technology, CRC Press, pp. 324-325.

19 M. S. Dresselhaus, A. Jorio, M. Hofmann, G. Dresselhaus, and R. Saito, Nano Lett. 10, 751 (2010).

20 F. Giannazzo, S. Sonde, V. Raineri, G. Patane, G. Compagnini, F. Aliotta, R. Ponterio, and E. Rimini, Phys. Status Solidi C 71251 (2010).

21 Y. Dan, Y. Lu, N. J. Kybert, Z. Luo, and A. T. C. Johnson, Nano Lett. 9, 1472 (2009).

22 Z. Cheng, Q. Zhou, C. Wang, Q. Li, C. Wang, and Y. Fang, Nano Lett. 11, 767 (2011).

23 A. V. Butenko, Dm. Shvarts, V. Sandomirsky, Y. Schlesinger, and R. Rosenbaum, J. Appl. Phys. 88, 2634 (2000).

24 S. Lara-Avila, K. Moth-Poulsen, R. Yakimova, T. Bjornholm, V. Falko, A. Tzalenchuk, and S. Kubatkin, Adv. Mater. 23, 878 (2011).

25 A. Scott, A. Dianat, F. Borrnert, A, Bachmatiuk, S. Zhang, J. H. Warner, E. Borowiak-Palen, M. Knupfer, B. Buchner, G. Cuniberti, and M. H. Rummeli, Appl. Phys. Lett. 98, 073110 (2011).

26 J. Biscoe and B. E. Warren, J. Appl. Phys. 13, 364 (1942).

27 J. Kotakoski, A. V. Krasheninnikov, U. Kaiser, and J. C. Meyer, Phys. Rev. Lett. 106, 105505 (2011). 


\section{Figure captions:}

FIG. 1: (Color online) A typical temperature profile for the deposition of graphene-like thin films on $\mathrm{Si}_{3} \mathrm{~N}_{4} / \mathrm{Si}$. The shadowed region indicates the growth time.

FIG. 2: (Color online) Raman spectra $(514 \mathrm{~nm})$ of samples A, B and C. For all samples, distinct G, 2D, D and G+D peaks are observed.

FIG. 3: (Color online) (a) Optical micrograph of the $\sim 6 \times 6 \mathrm{~mm}^{2}$ samples. Top row: bare substrate (left), sample $A_{1}$ (middle), and sample $B$ (right). Bottom row: sample $C$ (left) and sample $A_{2}$ highlighting the fabricated Hall-bar devices (right). (b) Optical micrograph of a typical Hall-bar device fabricated by standard photolithography and $\mathrm{O}_{2}$ plasma etching on sample $\mathrm{A}$.

FIG. 4: Electric field effect observed in Hall-bar structures fabricated on samples (a) A and (b) B. Sheet resistance $R_{S}$ is plotted against back-gate voltage $V_{G}$. Inset: $I-V$ curves of the devices fabricated on samples (a) $\mathrm{A}$ and (b) $\mathrm{B}$, showing linear ohmic behavior. $R_{s}$ values are calculated from four-probe resistance measurements (not shown). 